\title{
Acolhimento: concepções e práticas dos profissionais que compõem as equipes interdisciplinares do Hospital Universitário de Brasília
}

\author{
User Embracement: conceptions and practices of the professionals \\ who are in interdisciplinary services at Hospital Universitário de \\ Brasília
}

\section{Acogimiento: concepciones y prácticas de los profesionales que componen los equipos interdisciplinarios del Hospital Universitário de Brasilia}

Marina Corrêa de Faria ${ }^{1}$ Cláudia Regina Merçon de Vargas ${ }^{2}$

\begin{abstract}
RESUMO: Este trabalho teve o objetivo de conhecer a percepção dos profissionais que vivenciam sua prática de trabalho em equipes interdisciplinares de serviços inseridos no Hospital Universitário de Brasília (HUB) da Universidade de Brasília (UnB) sobre o acolhimento. Pretendeu-se estimular a reflexão sobre o acolhimento; conhecer as bases teóricas que o fundamentam e os seus objetivos; além de identificar a compreensão dos profissionais acerca do atendimento das necessidades dos usuários Trata-se de um estudo qualitativo descritivo, em que os dados foram coletados por meio de questionário com perguntas abertas. Participaram da pesquisa 14 profissionais, integrantes das equipes do Centro Multidisciplinar do Idoso, do Projeto Com-Vivência e da Unidade de Assistência de Alta Complexidade em Oncologia. Constatou-se que as concepções de acolhimento estão de acordo com os conceitos e reflexões dos autores referenciados na literatura e a identificação de elementos como vínculo, escuta, fornecimento de informações, integralidade e reconhecimento das demandas contribuem para uma compreensão coerente com os princípios do Sistema Único de Saúde (SUS) e com a Reforma Sanitária. A legislação do SUS e da Política Nacional de Humanização respaldam as bases teóricas que fundamentam a prática do acolhimento pelas pesquisadas. Concluiu-se que, embora haja alinhamento teórico com os fundamentos do acolhimento, é necessário ampliar a sua concepção para além de uma atividade específica, exigindo um investimento maior na habilidade de cuidar e estar atento para acolher, o que contribuiria para melhor atender as necessidades dos usuários.
\end{abstract}

Palavras-chave: Acolhimento, Equipe Interdisciplinar de Saúde, Vínculo.

ABSTRACT: This work aimed to explore perceptions of the professionals who compose the

1 Assistente Social, graduação em Serviço Social na Universidade de Brasília, finalizando o Programa de Residência Multiprofissional em Atenção Oncológica - Serviço Social no Hospital Universitário de Brasília (HUB). Brasília, Distrito Federal, Brasil. Email: marinacorrea10@gmail.com

2 Assistente Social, mestrado em Ciências da Saúde pela Universidade de Brasília. Assistente Social do Serviço de Estudos e Atenção a usuários de Álcool e outras Drogas (SEAD) localizado no Hospital Universitário de Brasília (HUB). Brasília, Distrito Federal, Brasil.

ISSN 1982-8829 Tempus, actas de saúde colet, Brasília, 11(3), 163-178, 2017 - Epub mar, 2018 
interdisciplinary teams of the Hospital Universitário de Brasillia (HUB) [Brasilia University Hospital] of the Universidade de Brasilia (UnB) [University of Brasilia] about user embracement. It was intended to stimulate reflection on embracement; to know its theoretical bases and objectives; in addition to identifying the professionals' understandings about the answers to users' needs. This is a qualitative descriptive study, in which the data were collected through a questionnaire with open questions. A total of 14 professionals participated in the study, members of the Centro Multidisciplinar do Idoso [Multidisciplinary Center of the Elderly], the Projeto Com-Vivencia [Com-Vivencia Project] and the Unidade de Assistência de Alta Complexidade em Oncologia [Oncology High Complexity Assistance Unit]. It was found that the user embracement conceptions are in accordance with the concepts and reflections of the authors referenced in the literature and the identification of elements such as bonding, listening, providing of information, completeness and recognition of the demands contribute to an understanding which cohere with the principles of the Sistema Único de Saúde (SUS) [Unified Health System] and the Reforma Sanitária [Health Reform]. The SUS legislation and the Politica Nacional de Humanização [National Humanization Policy] support the theoretical bases that underlie the practice of user embracement by the objects. It was concluded that, although there is a theoretical alignment with the foundations of the user embracement, it is necessary to extend its conception beyond a specific activity, requiring a greater devotion in the ability to care and be attentive to embrace, which would contribute to better meet the needs of users.

Keywords: User Embracement, Health Interdisciplinary Team, Bond.

RESUMEN: Este trabajo tuvo el objetivo de conocer las concepciones de los profesionales que componen los equipos interdisciplinares del Hospital Universitario de Brasília (HUB) de la Universidade de Brasilia (UnB) sobre el acogimiento. Se pretendía estimular la reflexión sobre el acogimiento; conocer las bases teóricas que lo fundamentan y sus objetivos, además de identificar la comprensión de los profesionales acerca de la atención a las necesidades de los usuarios. Se trata de una investigación cualitativa descriptiva, según la cual. los datos fueron recolectados por intermedio de un cuestionario con preguntas abiertas. Participaron de la investigación 14 profesionales, participantes de los equipos del Centro Multidisciplinar do Idoso, del Projeto Com-Vivência y de la Unidade de Assistência de Alta Complexidade em Oncologia. Se constató que las concepciones del acogimiento están de acuerdo con los conceptos y reflexiones de los autores referenciados en la literatura y la identificación de elementos como enlace, escucha, suministro de informaciones, integralidad y reconocimiento de las demandas contribuyen a una comprensión del acogimiento coherente con los principios del Sistema Único de Saúde (SUS) y con la Reforma Sanitaria. La legislación del SUS y de la Política Nacional de Humanização apoyan la práctica del acogimiento por las profesionales. Se concluyó que, aunque haya alineación teórica con los fundamentos del acogimiento, es necesario ampliar su concepción más allá de una actividad específica, exigiendo una inversión más grande en la capacidad de cuidar y estar atento para acoger, lo que contribuiría para mejorar las respuestas a las necesidades de los usuarios.

Palabras clave: Acogimiento, Equipo Interdisciplinario en Salud, Enlace.

\section{INTRODUÇÃO}

O acolhimento vem sendo discutido no campo da saúde e compreendido como estratégia fundamentada no princípio da integralidade, no âmbito da política de saúde e especialmente como uma diretriz da Política Nacional de Humanização (PNH).

A Política Nacional de Humanização, criada pelo Ministério da Saúde em 2003, aborda a

ISSN 1982-8829 Tempus, actas de saúde colet, Brasília, 11(3), 163-178, 2017 - Epub mar, 2018 
Humanização, como um conjunto de estratégias para alcançar a qualificação da atenção e da gestão em saúde no SUS, estabelece-se, portanto, como a construção/ativação de atitudes ético-estético-políticas em sintonia com um projeto de co-responsabilidade e qualificação dos vínculos interprofissionais e entre estes e os usuários na produção de saúde. ${ }^{(1)}$

Estabelecida com o objetivo de atender à necessidade de avanço e qualificação do Sistema Único de Saúde (SUS) tanto na atenção ao usuário como no processo de trabalho de gestores e profissionais da área de saúde, a Política Nacional de Humanização é abordada de forma transversal às demais políticas de saúde. ${ }^{(1)}$

O acolhimento também deve ser entendido como uma ferramenta tecnológica de intervenção na qualificação da escuta, construção de vínculo, garantia do acesso com responsabilização e resolutividade nos serviços. Como ação tecnicoassistencial, o acolhimento permite a análise dos processos de trabalho voltada para as relações, estimulando mudanças e promovendo o reconhecimento do usuário como sujeito e participante ativo no processo de produção da saúde. ${ }^{(2)}$

A compreensão de acolhimento é adotada pelo Núcleo Técnico da Política de Humanização como ato ou efeito de acolher, sendo sinônimo de ação de aproximação, ou seja, uma atitude de inclusão. Assim,

\footnotetext{
O acolhimento como postura e prática nas ações de atenção e gestão nas unidades de saúde favorece a construção de uma relação de confiança e compromisso dos usuários com as equipes e os serviços, contribuindo para a promoção da cultura de solidariedade e para a legitimação do sistema público de saúde. ${ }^{(2)}$
}

Nesta perspectiva e considerando a importância de aprofundar as reflexões acerca do acolhimento em saúde, estabeleceu-se o objetivo central de conhecer a percepção dos profissionais que vivenciam sua prática de trabalho em equipes interdisciplinares de serviços inseridos no Hospital Universitário de Brasília (HUB) da Universidade de Brasília (UnB).

\section{METODOLOGIA}

Optou-se por adotar no presente estudo uma abordagem qualitativa de caráter descritivo por considerar que:

[...] o método qualitativo se aplica ao estudo da história, das relações, das representações, das crenças, das percepções e das opiniões, produtos das interpretações que os humanos fazem a respeito de como vivem, constroem seus artefatos e a si mesmos, sentem e pensam. ${ }^{(3)}$

Com a finalidade proposta pela pesquisa, elaborou-se um questionário com perguntas abertas que foram dirigidas aos profissionais do Centro Multidisciplinar do Idoso (CMI), do Projeto Com-Vivência e da Unidade de Assistência de Alta Complexidade em Oncologia (UNACON). Os Serviços foram escolhidos por apresentarem características de trabalho desenvolvido na perspectiva interdisciplinar, composto por profissionais de diferentes áreas, com a realização de atividades em

ISSN 1982-8829 Tempus, actas de saúde colet, Brasília, 11(3), 163-178, 2017 - Epub mar, 2018 
conjunto e a discussão coletiva dos casos em equipe.

Os critérios de inclusão dos participantes foram: estarem inseridos nos Serviços selecionados para a coleta de dados e realizarem contato direto com os usuários.

Foram excluídos da pesquisa os profissionais que não estão inseridos nas equipes interdisciplinares dos Serviços selecionados, visto que apesar de existir no HUB outras equipes multiprofissionais, nem sempre desenvolvem trabalhos na perspectiva interdisciplinar. Excluiu-se também os profissionais que se recusaram a participar da pesquisa.

Os sujeitos da pesquisa foram contatados pessoalmente pela pesquisadora no local de trabalho, por e-mail e por mensagem de texto via telefone, individualmente e no grupo de trabalho do WhatsApp. Nota-se que os convites realizados pessoalmente obtiveram maior número de respostas.

Os questionários foram aplicados nos dois últimos meses do ano de 2017 com catorze profissionais do HUB, dos quais quatro são do CMI, um do Projeto Com-Vivência e nove do UNACON, de um total de sete, quatro e 24 profissionais que integram as respectivas equipes interdisciplinares. Apesar dos esforços depreendidos pela pesquisadora em contatar os profissionais, houve dificuldade de adesão dos mesmos à pesquisa, sobretudo nas equipes mais numerosas e com a categoria médica, o qual não há nenhuma contribuição neste estudo. Presume-se que a rotina sobrecarregada de trabalho, o excesso de demandas e a falta de interesse dos profissionais em descrever, refletir e discutir sua prática de trabalho contribuíram para a baixa adesão à pesquisa. Houve, também, dificuldades em encontrar determinados profissionais devido ao horário de atendimento e a rotatividade dos serviços.

Os dados foram submetidos à técnica de análise de conteúdo proposta por Bardin, que para a análise de respostas às questões abertas, sugere a organização dos dados em categorias e a classificação de elementos de significação contidos nas respostas. (4)

A partir das informações obtidas nas respostas dos questionários, fez-se primeiramente uma análise descritiva dos seguintes dados sociodemográficos: caracterização dos sujeitos (gênero, idade, área de formação, grau de escolaridade ano de formação), vínculo institucional, tempo de trabalho na área de saúde e no HUB bem como na equipe interdisciplinar. Posteriormente, agrupou-se as demais respostas em categorias temáticas criadas a priori que elucidam a concepção de acolhimento, seu objetivo no serviço, bases teóricas que o fundamentam e acolhimento como intervenção profissional. E, por fim, identifica-se a compreensão acerca do atendimento das necessidades dos usuários. Os participantes foram identificados aleatoriamente de F1 a F14.

Essa pesquisa foi aprovada pelo Comitê de Ética e Pesquisa de Ciências Humanas e Sociais da Universidade de Brasília, CAAE: 75187317.8.0000.5540, e todos os sujeitos concordaram em participar mediante assinatura do Termo de Consentimento Livre e Esclarecido, conforme a 
Resolução 466/2012 do Conselho Nacional de Saúde.

\title{
CONTEXTUALIZAÇÃO DOS CENÁRIOS INVESTIGADOS
}

O Hospital Universitário de Brasília é uma instituição pública federal que surgiu em 1972, durante a ditadura militar e constitui-se em uma unidade da Universidade de Brasília (FUB). Em 1979, por meio de convênio com o Instituto Nacional da Assistência Médica e Previdência Social (Inamps), passou a ser considerado como hospital de ensino da UnB e em 2005 o HUB foi certificado pelos Ministérios da Educação e da Saúde como hospital escola ${ }^{(5)}$. Os atendimentos são exclusivamente gratuitos, pelo Sistema Único de Saúde (SUS) vinculado à Secretaria de Saúde do Distrito Federal (SES-DF).

Em 2013, o hospital passou a ser administrado pela Empresa Brasileira de Serviços Hospitalares (EBSERH), com personalidade jurídica de direito privado e patrimônio próprio. Observa-se que nestes cinco anos de gestão do HUB pela EBSERH as questões relacionadas à falta de financiamento, crise orçamentária, insuficiência de recursos humanos e materiais, além da dificuldade de acesso dos usuários aos serviços e fragilidade da rede de atenção à saúde nos diferentes níveis de complexidade para atendimento das demandas, são problemas persistentes.

No início do movimento do Ministério da Educação de repassar a gestão dos Hospitais Universitários para terceiros, Sodré et al, 2013, ${ }^{(6)}$ já alertava sobre a complexidade da questão e suas implicações no processo de ensino, destacando:

Torna-se necessário conhecimento e profunda reflexão acerca dessa alternativa de gestão, pois não é difícil compreender que os conflitos existentes em torno da gestão dos HUFs é também reflexo da não efetivação plena do SUS, conforme elaborado e defendido pelo movimento da Reforma Sanitária a partir de um embate de forças nas décadas de 1970 e 80.

Colaboram com essas reflexões Steytler e Oliveira, 2013, (7), afirmando que:

\begin{abstract}
Há que reconhecer os avanços ocorridos no campo da saúde, principalmente nos aspectos legais a partir da Constituição Federal de 1988. Porém, as ofensivas que o SUS vem recebendo desde sua implantação faz com que o SUS almejado, "aquele" como direito universal,_com qualidade, público, integral e com participação da população esteja muito distante de ser efetivamente conquistado. Tal contexto também é vivenciado no HUB, que nos últimos anos sofre, assim como ocorre nos demais hospitais universitários do Brasil, com a falta de financiamento e a crise orçamentária.
\end{abstract}

Outro aspecto que merece ser destacado e apresenta-se como um importante desafio diz respeito à necessidade da comunidade universitária ampliar e aprofundar as reflexões sobre a autonomia da Universidade enquanto instituição de ensino, pesquisa e extensão frente a este novo modelo de gestão implantado nos Hospitais Universitários.

ISSN 1982-8829 Tempus, actas de saúde colet, Brasília, 11(3), 163-178, 2017 - Epub mar, 2018 


\section{Centro Multidisciplinar do Idoso (CMI)}

O Centro Multidisciplinar do Idoso (CMI), inaugurado em 2002 no Hospital Universitário de Brasília, destina-se a atender idosos, exceto nos casos diagnosticados com demência precoce, que apresentam déficit cognitivo e algum tipo de demência. $\mathrm{O}$ ingresso dos pacientes é feito por encaminhamento médico das várias clínicas do HUB e também de outras unidades de saúde da região leste. Os pacientes são avaliados e encaminhados ao atendimento multidisciplinar, em que será elaborado em reunião de equipe o plano terapêutico a ser seguido.

Compõem a equipe do CMI médicos geriatras, fisioterapeuta, assistente social, neuropsicóloga, recepcionista, professoras dos cursos de Odontologia, Farmácia, Fonoaudiologia e Enfermagem, estagiários e residentes dos programas de residência médica e multiprofissional.

No CMI são desenvolvidas as seguintes atividades: atendimento familiar, testes neuropsicológicos, consultas e atendimentos com os profissionais que compõem a equipe, visitas domiciliares, atividade de educação permanente denominada clube de revista, reunião em equipe, visitas aos pacientes internados em acompanhamento pela Geriatria.

\section{Projeto Com-Vivência}

O Projeto Com-Vivência surgiu em 1996 como uma atividade de extensão universitária de ação contínua, vinculado ao Decanato de Extensão da Universidade de Brasília, destinado a atender

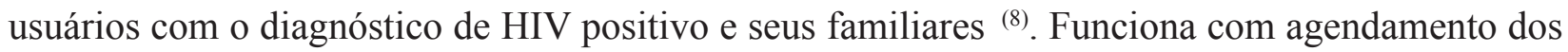
pacientes e atende qualquer demanda relacionada com a temática.

Aequipe doProjeto Com-Vivênciaé composta por profissionais da Medicina(infectologistas), da Enfermagem, da Farmácia, do Serviço Social e da Psicologia, recepcionista, residentes da Medicina e multiprofissionais, além de estagiários. Os profissionais atuam em conjunto com a equipe de Doenças Infecto-Parasitárias (DIP) do HUB.

São desenvolvidas as seguintes intervenções: atendimento individual ao paciente e aos familiares, rodas de conversa, atendimento e consultas com os profissionais da equipe, visita multiprofissional aos pacientes internados na enfermaria da Clínica Médica e reuniões científicas.

\section{Unidade de Assistência de Alta Complexidade em Oncologia (UNACON)}

O HUB, em 2009, inaugurou o Centro de Alta Complexidade em Oncologia (CACON) e no início de 2017, em decorrência das novas contratualizações, o Centro é habilitado para Unidade de Assistência de Alta Complexidade em Oncologia (UNACON).

O UNACON consiste em uma unidade de tratamento ambulatorial para pessoas a partir ISSN 1982-8829 Tempus, actas de saúde colet, Brasília, 11(3), 163-178, 2017 - Epub mar, 2018 
de 18 anos de idade que possuem diagnóstico de câncer. $\mathrm{O}$ tratamento realizado por equipe interdisciplinar abrange a oncologia, radioterapia e possui aparelho de braquiterapia. A entrada dos usuários para tratamento oncológico pode ser feita por meio de encaminhamento médico interno para pessoas acompanhadas em outras áreas do mesmo hospital ou via regulação da SES-DF. Para a radioterapia, o usuário se inscreve no sistema de regulação da SES-DF e quanto ao tratamento hematológico, o fluxo de entrada funciona com agendamento dos pacientes após avaliação médica.

A equipe é composta por médicos hematologistas, médicos radioterapeutas, médicos oncologistas, físicos, médica psiquiatra, médica geriatra com formação em cuidados paliativos, tecnólogo, técnicos em radioterapia, enfermeiros, técnicos de Enfermagem, nutricionista, psicólogas, fisioterapeutas, professora fonoaudióloga, assistentes sociais, terapeuta ocupacional, técnicos administrativos, recepcionistas, residentes (médicos e multiprofissionais) e estagiários.

Semanalmente ocorrem as seguintes intervenções: acolhimento, atendimentos e consultas pelos profissionais da unidade, reuniões científicas e visita multiprofissional nos leitos destinados aos pacientes oncológicos internados na enfermaria da Clínica Médica.

\section{APRESENTAÇÃO E ANÁLISE DOS DADOS}

\section{Caracterização dos Participantes de Pesquisa}

Este item apresenta as características dos participantes do estudo, profissionais que compõem as equipes interdisciplinares do CMI, Projeto Com -Vivência e UNACON do HUB, pois de acordo com Chupel, 2008, ${ }^{(9)}$ : "quando se busca caracterizar algo ou alguém, busca-se, de fato, colocar em evidência, distinguir, apontar características peculiares do objeto".

Observa-se que no grupo de 14 pesquisadas todas são profissionais do gênero feminino com formação nas seguintes áreas: uma da Administração, três do Serviço Social, duas da Enfermagem, duas da Fisioterapia, duas da Fonoaudiologia, uma da Odontologia e três da Psicologia. Todas possuem ensino superior, embora uma profissional ocupa cargo de nível médio como funcionária administrativa.

Análises a respeito da expressiva inserção das mulheres no mercado de trabalho em saúde indicam a importância de compreender as questões relacionadas ao mundo do trabalho e as especificidades do setor e serviços de saúde. Entre os motivos para explicar a expansão do nível de ocupação da mulher no mercado de trabalho, segundo Lavinas, 2001, (10), está a amplitude do processo de reestruturação produtiva e a expansão da economia de serviços.

Em relação à idade das pesquisadas, identifica-se uma faixa etária entre 27 e 52 anos de idade, das quais a maioria se encontra na faixa de 30 a 39 anos, seguida da faixa entre 40 e 49 anos de idade. Verifica-se também que o maior número de profissionais concluiu o ensino superior no 
período de 2002 a 2006, ou seja, possuem entre 11 e 15 anos de formação, conforme Gráfico I.

Gráfico I - Ano de formação e idade das profissionais pesquisadas

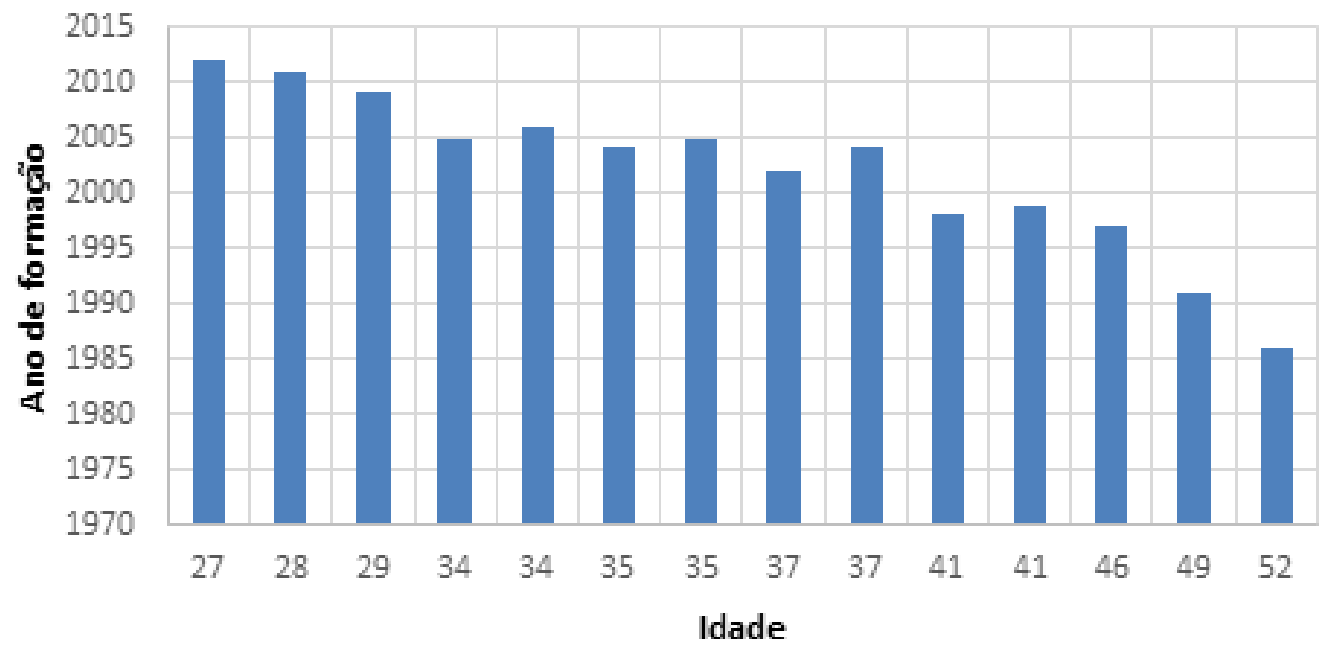

Vale ressaltar que das 14 pesquisadas, 14,2\% informaram não ter feito pós-graduação, $42,8 \%$ têm especialização e dentre estas, $14,2 \%$ são mestrandas, $14,2 \%$ possuem mestrado e $28,5 \%$ têm doutorado. Percebe-se que $85,7 \%$ das profissionais que integram as equipes dos serviços interdisciplinares pesquisados investem no aperfeiçoamento de suas competências e habilidades para atuarem na área de saúde e principalmente junto às populações específicas.

Considerando que o quadro de profissionais que atuam no HUB é composto por servidores que possuem vínculos com a Fundação Universidade de Brasília, com a EBSERH e voluntários, constata-se que 50\% possuem vínculo EBSERH e 50\% FUB, sendo que destas, 21,4\% são professoras da UnB. A variabilidade na composição das equipes ao mesmo tempo em que contribui, ao incentivar a produção do conhecimento e reflexão crítica acerca do processo de saúde, pode dificultar o desenvolvimento do processo de trabalho e integração das equipes, em razão de diferentes fatores, como a diferenciação do regime de trabalho.

Em relação ao tempo na área de saúde, verifica-se que a metade possui entre 11 e 20 anos de trabalho, seguida de um a 10 anos de trabalho e em menor número por mais de 21 anos de trabalho na área de saúde. Nota-se que o maior número de profissionais iniciou a prática na saúde posteriormente à implementação do SUS.

No que diz respeito ao tempo de trabalho no HUB, a maioria desenvolve suas atividades na instituição há menos de quatro anos, das quais, apenas uma das profissionais atua há menos de um ano. Em seguida prevalece as que estão há mais de dez anos, somente uma tem seis anos de permanência no HUB e outra está há 20 anos trabalhando no hospital.

Quanto ao tempo que o profissional está inserido na equipe interdisciplinar pesquisada, identifica-se que 64,2\% dos sujeitos fazem parte há menos de quatro anos e 35,7\% integram as equipes há mais de 10 anos. 
Os dados refletem as mudanças ocorridas na instituição em razão da entrada da EBSERH para gerir o HUB, a renovação do quadro de pessoal pelo término do contrato de trabalho temporário que existia há mais de 15 anos e a reestruturação dos serviços devido ao novo modelo de gestão.

\section{Concepções de acolhimento pelas profissionais}

$\mathrm{Na}$ análise das respostas, buscou-se refletir sobre as concepções de acolhimento presentes entre os diferentes profissionais que compõem as equipes interdisciplinares.

No conjunto de respostas, observa-se a concepção do acolhimento como um momento de recepção, porta de entrada e de repasse de informações: "Acolhimento é a recepção do paciente e familiar na unidade de oncologia". (F6) "É uma forma de receber os pacientes no Serviço, com apresentação geral de equipe, esclarecimento geral de dúvidas". (F8) "Na minha concepção, o acolhimento é uma atividade na qual procura-se receber o paciente e apresenta o Serviço, a Unidade, os profissionais." (F14) "Acolher o paciente passando as informações iniciais do tratamento e dos serviços oferecidos" (F5).

Uma profissional, entretanto, apresenta a concepção de acolhimento como triagem: "Os profissionais acolhem os pacientes que vem pela primeira vez no UNACON, realizando uma triagem para iniciar o tratamento." (F1). Esta concepção pode ser interpretada como um serviço de porta de entrada, porém com o objetivo de triar os pacientes para o atendimento no serviço. Outra profissional contrapõe a referida concepção afirmando que: 'Não se resume a ações isoladas e pontuais, como por exemplo, uma recepção confortável, de boa dimensão espacial, uma triagem administrativa, ou um bom encaminhamento para serviços especializados' (F4).

De acordo com Franco et al, 1999, ${ }^{(11)}$, o acolhimento enquanto uma das formas para reorganizar a lógica do serviço de saúde deve proporcionar o acesso dos usuários, acolher, ouvir e saber passar informações resolutivas acerca da demanda, considerando a disponibilidade do serviço. $\mathrm{O}$ enfoque em passar as informações pode ser observado na expressão de uma das profissionais: "Acolher o paciente passando as informações iniciais do tratamento e dos serviços oferecidos." (F5).

Ainda quanto à compreensão do acolhimento com o intuito de reorganização da lógica de trabalho, pode-se identificar na resposta da profissional, um aspecto colocado pelo autor ${ }^{(11)} \mathrm{em}$ relação à mudança do foco do médico para a equipe multiprofissional: “...procura-se dar uma sensação de segurança na instituição, no tratamento. Segurança de que as necessidades tanto fisicas quanto biopsicoespirituais, psicológicas, financeiras, dê algum tipo de auxílio ainda que não possam ser resolvidas. " (F14). Assim, além da equipe identificar demandas, ela se compromete a respondê-las conforme argumenta Franco et al ${ }^{(11)}$.

ISSN 1982-8829 Tempus, actas de saúde colet, Brasília, 11(3), 163-178, 2017 - Epub mar, 2018 
O acolhimento como possibilidade de ampliar a visão da atenção à saúde e das demandas dos usuários, respeitando suas especificidades, entendido também como diálogo e conteúdo de qualquer atividade assistencial e não necessariamente de uma atividade em particular, proposto por Teixeira ${ }^{(12)}$ surge nas seguintes respostas: "Em olhar o paciente como um todo." (F7) e "É olhar o idoso de uma maneira mais ampla, escutando esse idoso, apesar de que ele pode ter as queixas específicas dele, a gente tem que levar isso em consideração. A gente tem que dar importância, o acolhimento vai além do ouvir." (F9). Esta compreensão possibilita um olhar integral e a comunicação entre os componentes das equipes com os pacientes.

As profissionais também citaram a concepção de acolhimento como uma forma de olhar, destacando as linhas de cuidado e os diferentes níveis de atenção na construção do plano terapêutico discutido em conjunto pela equipe conforme recomenda Silva e Alves (13). "É a concepção do olhar, da linha de cuidado na área de oncologia de uma forma completa, que vai valorizar desde a atenção primária, da atenção secundária/terciária/ quaternária e depois um retorno para a atenção primária nos casos paliativos." (F10). No entanto, a compreensão do acolhimento como espaço capaz de incluir a voz do usuário na construção de projetos terapêuticos, apontada pelos referidos autores, não foi reconhecida nas respostas das participantes.

Outra concepção encontrada foi a que envolve o estabelecimento de vínculo do usuário com a equipe de saúde: "é necessário um atendimento com foco em fortalecimento de vínculo." (F12); “... deve ser atravessado por processos de responsabilização, buscando a criação de vínculo a partir da escuta de problemas, troca de informações, mútuo reconhecimento de direitos e deveres, e decisões que possibilitem intervenções pertinentes e eficazes em torno das necessidades dos usuários...” (F4). Percebe-se que nesta concepção há o reconhecimento do acolhimento como uma prática que possibilita a construção de vínculo com a equipe e que o profissional assume uma postura de escuta e compromisso com as necessidades dos usuários conforme evidenciado na Política ${ }^{(14)}$.

O estabelecimento do vínculo favorece o conhecimento e o aprofundamento da realidade do usuário por parte dos profissionais, de modo que as soluções dos problemas e a melhoria dos serviços sejam compartilhadas por ambos. De acordo com Ilha et al, ${ }^{(15)}$, "o vínculo liga, aproxima, permite envolvimento mútuo entre sujeitos (...). Além do mais, o vínculo possui uma estreita relação com a prática de cuidados, uma vez que ambos promovem sintonia, troca de afetos e convivência potencialmente reconstrutora de autonomias".

A respeito desta compreensão, Matumoto ${ }^{(16)}$ salienta que o acolhimento é um processo de relações humanas, pois deve ser realizado por todos os trabalhadores de saúde nos vários momentos e tipos de atendimento. Assim, o acolhimento representa mais do que um uma ação pontual restrita à porta de entrada no serviço, deve estar presente ao longo de todo o tratamento de saúde. 
Analisando os aspectos presentes nas concepções de acolhimento das pesquisadas, identificou-se que elementos como vínculo, forma de olhar, escuta, fornecimento de informações, integralidade e identificação das demandas certamente contribuem para uma compreensão de acolhimento coerente com os princípios do SUS e com a Reforma Sanitária, cuja proposta pautase na concepção ampliada de saúde e na garantia dos direitos sociais, embora haja uma frágil compreensão acerca de alguns elementos essenciais, tais como a participação ativa dos usuários na construção do plano terapêutico.

\section{Objetivos do acolhimento no CMI, Projeto Com-Vivência e UNACON}

O presente item expõe os objetivos do acolhimento destacados pelos profissionais nos serviços em que estão inseridos.

No CMI, as profissionais indicam os seguintes objetivos do acolhimento: "Atendimento multidisciplinar com a intenção de avaliar o paciente e contexto em que encontra-se inserido, para elaboração do plano de cuidados." (F2); "Entender cada paciente em sua complexidade biopsicossocial." (F11); "Tratar o paciente de maneira integrada. " (F7); "A gente amplia e olha esse idoso de uma maneira geral para poder priorizar o cuidado desse idoso, vê o que é mais importante ou o que é prioritário em termos de organização hierárquica. " (F9). Entende-se que nesta equipe os objetivos do acolhimento condizem com a concepção de saúde integral e à noção de complementariedade das diferentes visões dos profissionais no planejamento do cuidado.

No UNACON, os objetivos apontados pelas participantes são: “O objetivo é apresentar o serviço, avaliar as necessidades.” (F14) ;“O objetivo do acolhimento é receber o paciente e familiar na unidade de oncologia passando informações básicas e essências neste primeiro contato.” (F6); "Orientar os pacientes quanto à realização do tratamento na oncologia e outros serviços." (F1). Diante destes objetivos pode-se dizer que a ideia da socialização da informação está presente na equipe bem como o reconhecimento das demandas de saúde dos usuários atendidos no Serviço. A respeito dessa questão, Silva, ${ }^{(17)}$ reflete que "a socialização das informações é um componente fundamental para viabilização de direitos, pois se apresenta como uma ação de fortalecimento do usuário para acessar esses direitos e para mudar a sua realidade.”.

No Projeto Com-Vivência, o objetivo do acolhimento é voltado para "vincular o paciente ao serviço e promover adesão ao tratamento." (F12). Quanto aos aspectos que podem contribuir ou não para a adesão do paciente a determinado serviço, ou seja, a vinculação institucional e a formulação do desejo de realizar o tratamento, nota-se o investimento da equipe no estabelecimento do vínculo entre profissionais e usuários.

\section{As bases teóricas do acolhimento na perspectiva das pesquisadas}

ISSN 1982-8829 Tempus, actas de saúde colet, Brasília, 11(3), 163-178, 2017 - Epub mar, 2018 
No que diz respeito à visão das participantes acerca das bases teóricas do acolhimento, constata-se que quase a metade das profissionais afirma que desconhecem os seus fundamentos. Assim, deve-se considerar que um número expressivo de profissionais está distante da relação entre os aspectos teóricos e a intervenção realizada nos serviços.

Em relação às profissionais que indicaram os aspectos teóricos que orientam sua prática de acolhimento, o SUS e a Política de Humanização foram apresentados de forma significativa, enquanto o suporte teórico específico da área de formação profissional foi citado em menor escala.

Em várias respostas das participantes foi citado: "Sistema Único de Saúde; Política Nacional de Humanização; Política Nacional de Saúde da Pessoa Idosa; Portaria 249/2002 do Ministério da Saúde (sobre criação de centros de referência de atendimento à pessoa idosa)." (F2); "Política Nacional de Humanização" (F11); "O SUS; HUMANIZA SUS." (F4); "Acesso do usuário aos serviços de saúde como cidadão protegido pela Seguridade Social.” (F5). Além disso, duas participantes apontaram referências específicas da área de formação: “psico-oncologia” (F14) e "Terapia Cognitivo-Comportamental". (F12).

Identificou-se ainda, a questão da interdisciplinaridade: "Eu acho que tem muito a questão da humanização, da interdisciplinaridade.” (F9).

O acolhimento constitui-se em uma importante estratégia para efetivação dos princípios e diretrizes do SUS e nota-se que a integralidade está presente na resposta da profissional: "Humanização, integralidade." (F5)_

Por fim, observa-se que mais da metade das participantes indica a PNH, 2004, (1) como base teórica para fundamentar o acolhimento definido como sendo a recepção do usuário, em que os profissionais devem se responsabilizar de forma integral para escutar sua demanda, permitindo expressar todos os sentimentos ali expostos, porém preocupando-se em colocar os limites necessários, desde que garanta uma atenção resolutiva, haja vista a articulação com os serviços de saúde para a continuidade da assistência.

\section{Acolhimento como intervenção profissional}

Ao conhecer a visão das pesquisadas sobre o acolhimento como intervenção profissional, ressalta-se que quase a totalidade as participantes da pesquisa avaliam o acolhimento como uma intervenção. Enfatiza-se que a metade das profissionais respondeu somente "sim", sem discorrer sobre a questão e as que complementaram a afirmação trouxeram: "Compromisso ético em assegurar a qualidade no atendimento multidisciplinar." (F2) norteia o tratamento." (F7); "Inerente a todo o processo de tratamento, não se restringindo a um único momento." (F3); "Com certeza. Qualquer orientação que fazemos, qualquer pergunta, qualquer escuta, já é uma intervenção." (F9);“" o profissional além de ouvir o paciente, pode intervir dependendo da queixa, da dificuldade 
de alimentação, da dor, da perda de peso, da dificuldade de comunicação.” (F10). Apenas uma das pesquisadas não considera o acolhimento uma intervenção profissional, e expõe: (F13) "Não exatamente, mas serve como uma primeira avaliação.’(F13). Embora de forma não assertiva, traz a dimensão da avaliação no acolhimento.

Em relação a este assunto, Matumoto, ${ }^{(16)}$ reforça a intervenção profissional ao fazer alusão à temática do acolhimento na saúde:

No quotidiano concretizam-se as relações que caracterizam o trabalho em saúde e cristalizam suas práticas, isto é, transformam o atendimento em um ato. $\mathrm{O}$ encontro entre $\mathrm{o}$ trabalhador e o usuário traz à tona as necessidades do usuário que procurou o serviço de saúde, as necessidades do profissional que o atende, estando mediadas

\section{Acolhimento e atendimento das necessidades dos usuários}

Além das características descritas pelas pesquisadas, é fundamental saber se a intervenção acolhimento atende as necessidades dos usuários dos serviços.

No CMI, metade das entrevistadas referem que o acolhimento atende às necessidades dos usuários, e as demais se distribuíram igualmente nas respostas não e que atende parcialmente. As profissionais que dizem que o acolhimento atende as demandas dos usuários consideram que as orientações repassadas são suficientes para suprirem as necessidades. Aquelas que afirmam que não, justificam que: "as demandas apresentadas não serão supridas com apenas orientações iniciais, sendo necessário um acompanhamento para verificar se tais orientações foram seguidas." (F9). Já as que declaram que atende parcialmente, expressam que: "as orientações relacionadas à saúde e higiene bucal serão seguidas, porém há necessidades de reabilitação complexas que não são possíveis de serem atendidas no HUB." (F11).

No Projeto Com-Vivência acredita-se que a intervenção acolhimento atende às necessidades dos usuários. Argumenta-se que: "o acolhimento é algo fundamental no serviço onde atuo, pois, os pacientes chegam até nós com dúvidas acerca de como iniciar o acompanhamento médico e tratamento farmacológico, medo de sofrer preconceito pela equipe de saúde, continuação de projetos de vida e revelação do diagnóstico." (F12).

No UNACON, Por outro lado, quase a metade respondeu que a intervenção acolhimento atende às necessidades dos usuários, em menor escala expressam negativamente e, ainda, que atende parcialmente, "argumentam que não há espaço naquele momento para construir um plano de cuidado em conjunto pela equipe e que são muitas informações repassadas pelos profissionais nas quais os usuários não conseguem absorver tudo.” (F8). Apenas um profissional optou por não responder sobre a intervenção acolhimento e às necessidades dos usuários, por entender que esse questionamento não condiz com suas atribuições profissionais. 
As profissionais que informam que sim, declaram que: "a intervenção contribui para desmistificar preconceitos, medos e pensamentos equivocados acerca do tratamento oncológico." (F4); "Colabora para esclarecer as dúvidas e auxilia na organização do tratamento.” (F13).

As participantes da pesquisa que reconhecem que a intervenção acolhimento não atende as necessidades dos usuários alegam: "não ser possível atender, pois algumas necessidades ultrapassam aquele espaço.” (F14). Sugerem como proposta de mudança: "uma apresentação mais pragmática, com áreas afins em conjunto para facilitar na compreensão do usuário e evitar a repetição das mesmas informações, sendo necessário haver outro momento para tirar dúvidas e dar as orientações profissionais." (F10).

\section{CONSIDERAÇÕES FINAIS}

Constatou-se que as concepções de acolhimento das pesquisadas estão de acordo com os conceitos e reflexões dos autores referenciados na literatura sobre o tema. Ao analisar as respostas sobre as bases teóricas que fundamentam a prática do acolhimento, verifica-se que a maioria se pauta na legislação do SUS, na PNH e demais políticas de saúde. Mesmo assim, observa-se que predomina uma visão do acolhimento como primeiro atendimento e não como uma postura que deve estar presente durante toda a atenção à saúde. Essa visão repercute na participação do usuário em seu processo de tratamento, cujo protagonismo como parte fundamental do acolhimento não foi identificado nas opiniões expressas pelas pesquisadas.

Identificou-se ainda que a presença de elementos como vínculo, escuta, fornecimento de informações, integralidade e identificação das demandas contribuem para uma compreensão de acolhimento coerente com os princípios do SUS e com a Reforma Sanitária cuja proposta pauta-se na concepção ampliada de saúde e na garantia dos direitos sociais. Percebe-se que grande parte das profissionais investem no aperfeiçoamento de suas competências e habilidades para atuarem na área de saúde, principalmente junto às populações específicas.

Verificou-se que em uma equipe interdisciplinar os objetivos do acolhimento condizem com a concepção de saúde integral e à noção de complementariedade das diferentes visões dos profissionais no planejamento do cuidado. Em outra equipe, destaca-se a socialização da informação como objetivo central do acolhimento, no entanto, houve o questionamento dentre as profissionais sobre a compreensão das informações pelos usuários. Outro serviço aponta a construção do vínculo entre profissionais e usuários como o principal objetivo do acolhimento.

Pode-se afirmar que um dos desafios que as reflexões deste estudo colocam aos profissionais dos serviços é ampliar a concepção de acolhimento para além da atividade específica e ser considerado como um processo de relações humanas, pois deve ser realizado por todos os trabalhadores de saúde nos vários momentos e tipos de atendimento. Com isso, exige-se um investimento maior na habilidade de cuidar e estar atento para acolher. Investimento este que contribuiria para melhor 
atender às necessidades dos usuários, já que várias pesquisadas apontaram que a intervenção acolhimento não alcança esse objetivo.

Outro aspecto que merece ser ressaltado diz respeito ao processo de trabalho, especialmente às mudanças na Política de Saúde e nas novas formas de gestão, que reforçam a sobrecarga de trabalho, a dificuldade de acesso pelos usuários e o excesso de demandas, repercutindo na falta de interesse dos profissionais em descrever, refletir e discutir sua prática de trabalho bem como as alternativas de enfrentamento.

O limite do estudo se deu em relação ao pouco tempo para coleta de dados e análise, em razão da demora da resposta da aceitação do projeto no Comitê de Ética e Pesquisa.

Cabe ressaltar que novos estudos sobre o tema devem ser realizados com o objetivo de aprofundar as reflexões a respeito das concepções de acolhimento bem como contribuir para o aperfeiçoamento das práticas de saúde.

\section{REFERÊNCIAS BIBLIOGRÁFICAS}

1.Brasil, Ministério da Saúde, Secretaria de Atenção à Saúde, Núcleo Técnico da Política Nacional de Humanização. HumanizaSUS - Política Nacional de Humanização: a humanização como eixo norteador das práticas de atenção e gestão em todas as instâncias do SUS Brasília: Editora Ministério da Saúde; 2004.

2. Brasil, Ministério da Saúde, Secretaria de Atenção à Saúde, Núcleo Técnico da Política Nacional de Humanização. Acolhimento nas práticas de produção de saúde. 2nd ed. Brasília: Editora do Ministério da Saúde; 2010.

3.Minayo MCdS. O desafio do conhecimento: pesquisa qualitativa em saúde. 9th ed. São Paulo: Hucitec; 2006.

4.Bardin L. Análise de conteúdo Lisboa: Edições 70; 1977.

5.Universidade de Brasília, Hospital Universitário de Brasília. Institucional. [Online]. [acessado em 2017 setembro 30. Disponível em: http://www.ebserh.gov.br/web/hub-unb/nossa-historia.

6.Sodré F, Littike D, Drago LMB, Perim MCM. Empresa Brasileira de Serviços Hospitalares: um novo modelo de gestão? Serviço Social \& Sociedade. 2013 abril-junho;(114): p. 365-380.

7.Steytler SJS, Oliveira Ad. Direito ou responsabilização das famílias no acompanhamento hospitalar. Argumentum. 2016 janeiro-abril; 8(1): p. 174-190.

8.Araújo NCAd. O Projeto Com-Vivência e o direito à saúde: Caracterização sócio-econômica e de saúde dos usuários. 2011.

9.Chupel CP. Acolhimento e Serviço Social: um estudo em hospitais estaduais da Grande Florianópolis. 2008.

10.Lavinas L. Empregabilidade no Brasil: inflexões de gênero e diferenciais femininos. Texto para discussão.

ISSN 1982-8829 Tempus, actas de saúde colet, Brasília, 11(3), 163-178, 2017 - Epub mar, 2018 
2001 setembro: p. 1-24.

11.Franco TB, Bueno WS, Merhy EE. O acolhimento e os processos de trabalho em saúde: o caso de Betim, Minas Gerais, Brasil. Cadernos de Saúde Pública. 1999 Abril; 15(2).

12. Teixeira RR. O acolhimento num serviço de saúde entendido como uma rede de conversações. [Online]; 2000 [acessado em 2017 dezembro 13. Disponível em: http://www.corposem.org/rizoma/acolhiconversa.htm.

13. Silva LGd, Alves MdS. O Acolhimento como ferramenta de práticas inclusivas de saúde. Revista de APS. 2008 janeiro-março; 11(1): p. 74-84.

14. Brasil, Ministério da Saúde, Secretaria de Atenção à Saúde, Núcleo Técnico da Política Nacional de Humanização. Acolhimento na gestão e o trabalho em saúde Brasília: Editora do Ministério da Saúde; 2016.

15. Ilha S, Dias MV, Backes DS, Backes MTS. Vínculo profissional - usuário em uma equipe da estratégia saúde da família. In: Cienc Cuid Saude 2014 Jul/Set; 13(3):556-562.

16. Matumoto S. O acolhimento: um estudo sobre seus componentes e sua produção em uma unidade da rede básica de serviços de saúde. 1998.

17. Silva MLLd. Um novo fazer profissional. In: Capacitação em serviço social e política social: Módulo 4. Brasília: UnB; 2000. p. 111-124.

Artigo apresentado em 07/03/2018 Artigo aprovado em 20/03/2018 Artigo publicado no sistema em 16/04/2018 